www.jmscr.igmpublication.org

Impact Factor 5.244

Index Copernicus Value: 5.88

ISSN (e)-2347-176x ISSN (p) 2455-0450

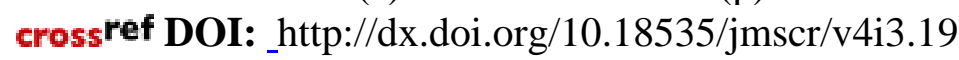

\title{
A Rare Case of Sirenomelia or Mermaid Syndrome in A Dizygotic Diamniotic Twin Pregnancy
}

\author{
Authors \\ Dr Manisha Chauhan ${ }^{1}$, Dr Saurabh Tomar ${ }^{2}$ \\ ${ }^{1,2}$ Senior Resident, S.N. Medical College, Agra (U.P) \\ ${ }^{1}$ Address: 18, Sulabh Vihar, Gailana Road, Agra-282007 (U.P) \\ Email: manishaaa0@gmail.com, Mob No.9458559955 \\ ${ }^{2}$ Address: MIG-15, New Housing Board Colony, Morena-476001(M.P) \\ Email:drsin100@gmail.com, Mob No.9165730003
}

\begin{abstract}
Sirenomelia is a rare congenital anomaly, not compatible with life, characterised by roatation and fusion of legs, which appears like fish tail, giving its common name" mermaid syndrome". genitourinary and gastrointestinal anomalies are frequently associated with it. very few cases are reported worldwide. We found a case in a dizygotic, diamniotic pregnancy with fusion of lower limbs. There were no external genitals and anal opening. Etiology of this syndrome remains unclear, however many hypothesis have been proposed mainly vascular steal phenomenon. Maternal diabetes mellitus and genetic factors are also associated. Diagnosis at early pregnancy by ultrasonography is possible and need careful attention so that termination of pregnacy can be done safely.
\end{abstract}

\section{Introduction}

Sirenomelia is a rare congenital anomaly, incompatible with life, characterized by rotation and fusion of legs, resulting in what often looks like a fish tail. It is commonly associated with abnormal kidney and bladder development, genital and gastrointestinal abnormalities.

More than half the cases of sirenomelia result in stillbirth and those born alive, usually die within a day or two of birth. Only a handful of patients with sirenomelia have been reported to have survived beyond the neonatal period notably "Milagros cerron", "Tiffany yorks", and "Shilahpepin".

\section{Case Report}

Mrs $\mathrm{X}$ is a $24 \mathrm{yr}$ old, primi patient, with spontaneous conception. She admitted to our hospital in last trimester of pregnancy as a case of 34 wk pregnancy with twin pregnancy with preeclampsia. No antenatal visit in first and second trimester. No H/o any drug intake, radiation exposure or diabetes. No family $\mathrm{H} / \mathrm{o}$ genetic or congenital malformation, diabetes or hypertension.

General and systemic examination were within normal limit except mild pallor (Hb-9.6gm\%), pedal edema and increased BP $(160 / 110 \mathrm{~mm} \mathrm{Hg})$ with urine albumin ++. All blood investigation and obstetric USG was done. Patient was put on 
labetalol 100mg BD. Emergency cesarean section was done as she passed in labour with frank leaking \& no cervical dilatation. First infant was healthy male of $2.2 \mathrm{Kg}$ with APGAR score 7 and 8 at $1 \& 5 \mathrm{~min}$. Second sac contained gelatinous material. second infant was of $2.0 \mathrm{~kg}$ with APGAR score 2/10 with multiple anomalies. Gross abnormalities include fusion of lower limbs and absence of external genitalia. Lower limbs were formed of short thigh, with legs and feet completely fused. Anal opening was absent with no external genitalia. sex of baby could not be identified. There were two separate placenta. Baby survived only for $2 \mathrm{hrs}$ postpartum. USG revealed complete absence of kidneys, urinary bladder, ureter and urethra with no potent connection of anal canal with intestinal tract. only single umblical artery could be identified. patients attendant were not ready for autopsy so only ultrasonographic findings were recorded.

\section{Discussion}

Sirenomelia is a very rare congenital anomaly affecting 1 in 1,00,000 babies and is 100 times more likely in identical twins. The etiology of sirenomelia remains unclear, however maternal diabetes mellitus, genetic predisposition, environmental factors and vascular steal phenomenon with single umbilical artery diverting blood supply and nutrients from the lower limb and body, have been proposed as possible causative factors.

According to garridoallepuz et al, discovery in mice can give some genetic basis. it occurs in mice lacking CYP261a1.An enzyme that degrades retinoic acid, and in mice that developed with reduced bone morphogenic protein signaling in caudal embryonic region. It suggest, that sirenomelia in humans may be associated with excess of RA signaling and deficit in Bmp signaling.

Although cause remains unknown, Two main pathogenic theories have been proposed:

1. aberrant and abnormal vascular pattern, postulates a primary vascular defect that leaves the caudal part to be hypoperfused. (vascular steal theory, steavenson et al ;1986)

2. primary failure of caudal somite formation( bolk;1899)

Other theories proposed were, pressure theory, caudal regression theory (duhamel;1961), neural tube over distension (gardner and brener; 1980), injury to caudal mesoderm (davis et al ;1970).

Fusion of lower extremity, bilateral renal agenesis, blind ending colon, single umbilical artery, absent external genitalia and imperforate anus were present in case and fit in the criteria proposed by Duhamel for the mermaid syndrome. Confusion still exists whether sirenomelia is a severe form of causal regression syndrome, consisting of spectrum of anomalies ranging from ectopic anus to sirenomelia. An embryologic insult to the caudal mesoderm, occurring between 28-32 days of gestation, is responsible for these malformation.

Rabbe et al reported the sonographic antenatal diagnosis of sirenomelia at 18 wks gestation as evidenced by (1) oligohydrominos (2) bilateral renal agenesis (3) fusion of lower extremities. Therapeutic abortion was implemented. Diagnosis of this fatal anomaly prior to 20 wks gestation is useful, so that option of pregnancy termination can be given to patient. Unfortunately this pt. did not have ANC booking \& USG obstetrics at early gestation.

It may be of 3 types depending upon severity and fusion of bones:

1. Sirenomeliadipus -two fused feet, two tibia, fused fibula, two femoral

2. sirenomeliaunipus -one rudimentary feet, two tibia, fused femoral

3. sirenomeliaapus absent feet, fused femora and tibia, absent fibula

Our case belonged to Ist type. 

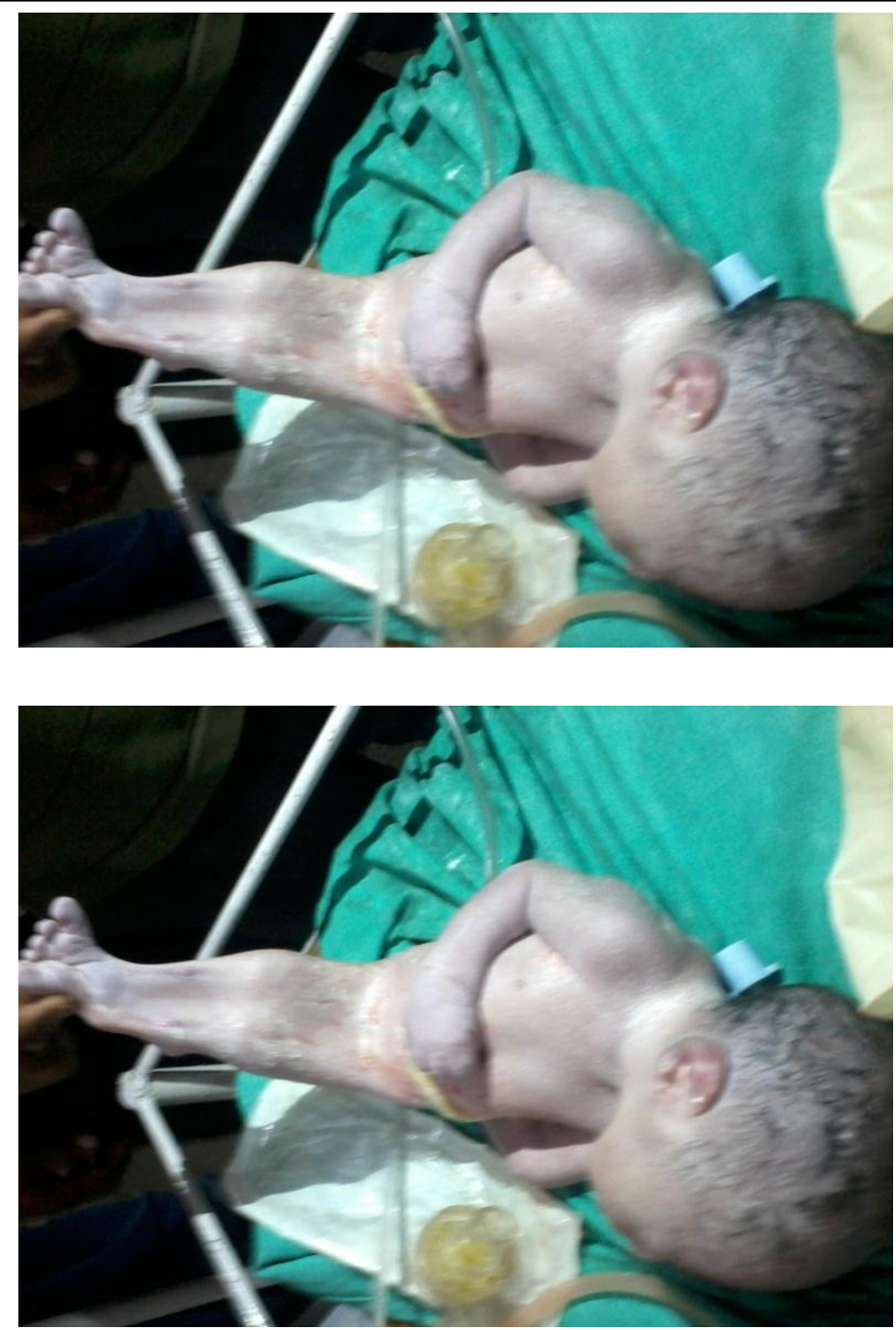

\section{References}

1. Duhamel B from the mermaid to anal imperforation : The syndrome of caudal regresson. Arch Dis Chil 1961:36:152154.

2. Goadlaw OG, McCoy Sibley RI, Allen BG, Kamanda WS Gullattee : Sirenomelia : Mermaid syndrome. J nat Med Ass 1988 : 80:343-346

3. Kallen B WinbergJ : Caudal mesoderm pattern of anomalies : From rectal agenesis to sirenomelia. Teratology 1974 : 90:99112

4. Rabbe R, Hamsberger HR, Lee TG, MukunoDH :Ultrasonographic antenatal diagnosis of mermaid syndrome : Fusion of lower extremity. J. Ultrasound Med 1983:2:463-464. 